\title{
LA DATACIÓN Y LA AUTORÍA DEL POEMA VITA MAHUMETI, ATRIBUIDO A EMBRICO DE MAINZ
}

\author{
THE DATING AND AUTHORSHIP OF THE POEM VITA \\ MAHUMETI, ATTRIBUTED TO EMBRICO OF MAINZ
}

\author{
FERNANDO GONZÁLEZ MUÑOZ \\ Universidad de A Coruña \\ http://orcid.org/0000-0002-1275-1448
}

\begin{abstract}
Resumen: El propósito de este artículo es revisar los problemas de la fecha de composición y la autoría de uno de los primeros relatos legendarios sobre el profeta Muhammad elaborados en la Europa central: la Vita Mahumeti atribuida a Embrico de Mainz. Después de presentar los indicios disponibles y las conjeturas de diferentes estudiosos, se propone una nueva hipótesis sobre la identidad del autor, que permite al mismo tiempo precisar la datación de la obra y sus posibles fuentes y sentido.
\end{abstract}

Palabras clave: Mahoma; Embrico de Mainz; datación; autoría; poesía latina medieval.

\begin{abstract}
The aim of this paper is to review the problems with the date of writing and the authorship of one of the first legendary accounts of the Prophet Muhammad written in Central Europe: the Vita Mahumeti, attributed to Embrico of Mainz. After presenting the available evidence and the conjectures of different scholars, a new hypothesis about the identity of the author is put forward, which at the same time enables us to clarify the dating of the work, its possible sources and meaning.
\end{abstract}

Keywords: Muhammad; Embrico of Mainz; dating; authorship; Medieval Latin poetry.

La Vita Mahumeti es un poema narrativo en latín que contiene una de las primeras versiones sobre la leyenda del profeta Muhammad elaboradas en la Europa central ${ }^{1}$. Consta de 1148 versos, organizados en 574 dísticos elegíacos con rima interna disilábica. He aquí un breve resumen del contenido.

En tiempos del emperador Teodosio, un anónimo mago se propone vengarse de la Iglesia por haber visto frustradas sus aspiraciones a ocupar el patriarcado de Jerusalén. Tras huir a Libia, este sujeto se introduce en el palacio de un noble y se gana la confianza de uno de sus servidores, Mamucius,

${ }^{1}$ En el apartado de Bibliografía citada se dan las referencias a todas las ediciones que ha conocido el texto: Beaugendre 1708 [reimpresión 1854]; Hübner 1935; Cambier 1962. 
que en otros lugares del poema recibirá el nombre de Mahumet. Entre ambos provocan la muerte del señor y la boda de Mamucius con la viuda, lo que otorga a éste la libertad y el encumbramiento social. Con objeto de convertir a Mamucius en soberano, el mago idea la estratagema de criar y amaestrar en secreto una criatura monstruosa. Muerto el rey de Libia, el mago propone al pueblo coronar a aquél que consiga poner el yugo a este animal, cosa que consigue fácilmente su discípulo. El siguiente paso es derogar la religión cristiana y promulgar una nueva ley basada en el libertinaje. El pueblo libio la acoge favorablemente, con la excepción de algunos que fueron perseguidos y martirizados. No obstante, Mamucius comienza a sufrir ataques de epilepsia, que serán aprovechados por el mago para reforzar la impostura, al convencer al pueblo de que los desvanecimientos responden a las visitas del rey a los cielos para debatir con Dios y los ángeles el gobierno del universo. Es en el curso de uno de estos viajes cuando Mamucius plantea la necesidad de extender la nueva religión más allá de las fronteras de Libia y arbitrar un rito de purificación de los pecados mediante el agua. Consagradas ya estas prácticas, Mamucius muere devorado por una piara de cerdos, pero el mago, una vez más, aprovecha esta circunstancia para sacralizar su figura y confirmar la nueva religión. Afirma que el rey ha subido a los cielos, introduce la prohibición de consumir carne de cerdo y construye para el cadáver un milagroso sepulcro flotante, que será objeto de veneración por las generaciones siguientes.

El poema ha llegado hasta nosotros en dieciséis manuscritos, buena parte de ellos datables en la segunda mitad del siglo XII. Contamos también con noticias o indicios de otros códices perdidos ${ }^{2}$. Por lo general, se trata de antologías de textos poéticos, donde predominan los pertenecientes al género hagiográfico y didáctico, con autores de la segunda mitad del siglo XI, como Godofredo de Reims y Marbodio de Rennes, y primera del XII, como Hildeberto de Lavardin y Hugo Metellus, pero que albergan también obras historiográficas, sobre todo crónicas y poemas de cruzada. Se trata, en todo caso, de una tradición manuscrita rica que, sin duda, es exponente del interés de las escuelas abaciales benedictinas y cistercienses de Francia y Alemania por este tipo de literatura durante los siglos XII y XIII. En efecto, entre los lugares donde se registra la presencia de algunos de los códices más antiguos se encuentran abadías de Normandía, como Saint-Amand-les-Eaux, de donde proviene el manuscrito conservado actualmente en la BNF de París, lat. 5129, o Notre-Dame de Clairmarais, origen del códice de Saint-Omer, Bibliothèque municipale, 115, y también de la Lorena, como Saint-Arnould de Metz, donde

\footnotetext{
${ }^{2}$ Para una descripción detallada de los códices remito a Hübner 1935, pp. 443-449; Cambier 1962, pp. 38-45.
} 
fue copiado el manuscrito depositado actualmente en la Staatsbibliothek de Berlín, Phill. 1694.

En tres de estos manuscritos, Paris, BNF, lat. 5129 (1145-1153), Douai, Bibliothèque Municipale 825 (ca.1173-1175) y 882 (1154-1159), se atribuye expresamente la Vita Mahumeti a Hildeberto de Lavardin, obispo de Le Mans entre 1097 y 1125 y arzobispo de Tours entre 1125 y 1133 . Hildeberto fue autor de diversas composiciones hagiográficas en verso, algunas de las cuales fueron copiadas en estos mismos códices. La atribución se mantuvo en la primera edición de la Vita Mahumeti, publicada por Antoine Beaugendre en 1708. Con todo, a la vista del contenido fabuloso del texto, el editor expresó el parecer de que se trataría de una obra de juventud, a manera de ejercicio o pasatiempo literario ${ }^{3}$.

Beaugendre se sirvió para su edición del único manuscrito que conocía: el de la BNF de París, pero a fines del siglo XIX las investigaciones de estudiosos alemanes sobre las antologías poéticas de la Edad Media latina fueron sacando a la luz muchos otros códices. Así, en 1891 Wilhelm Wattenbach llamó la atención sobre otros dos testigos, Berlin, Staatsbibliothek, Phill. 1694 (1175-1225), y Reims, Bibliothèque de la ville, 1073 (s. XIII), que transmitían, adjunta a la pieza, una breve composición en dísticos elegíacos titulada Vita auctoris. Este poemilla, que transcribimos y traducimos a continuación, da al autor del poema sobre Muhammad el nombre de Embrico y lo considera natural de Mainz ${ }^{4}$ :
Mens pia uult huius nomen cognoscere, cuius carmen sic redolet, suauis ut herba solet.
Ergo sciant noti cuncti pariterque remoti hec quod composuit carmina, dum studuit, Embrico, quem mores, genus exaltant et honores.
Forsitan et natus unde sit iste catus queritur: hoc mente describam non metuente.
Moguntinus erat, mater ut eius erat.
Nouerat auctores maiores atque minores, et quibus hos uoluit legerat ut decuit.
Philosophos legit, animo sacra scripta subegit.
Quicquid ei placuit, hoc satis exposuit.
Quem si uidisset quondam Naso coluisset prosa Sydonium, carmine Virgilium.

\footnotetext{
3 "Totum hoc nil nisi fabulam sapit, quam Hildebertus forte tunc iuuenis, et litteris adhuc humanioribus uacans potius quam seriis, necdum adhuc historia ualde peritus, exercitationis gratia in odium Mahumeticae sectae excogitauit et composuit"; Beaugendre 1708, p. 1277.

${ }^{4}$ En el apartado de Bibliografía se dan las referencias a todas las ediciones del poema: Wattenbach 1891, p. 113; Rose 1893, p. 402; Hübner 1935, pp. 488-489; Cambier 1962 , pp. 469-470, ésta última con traducción al francés.
} 
Quid moror in multis? Hunc si cognoscere uultis, aethicus et logicus extitit et phisicus.

Corpore florebat, in eo mens sancta manebat.

Debent ergo senes, cum pueris iuuenes,

eius opus clare bene quod descripsit amare,

ne magus ut pereant, uiuere dum ualeant.

El piadoso lector quiere conocer el nombre del autor

de este poema fragante como la suave hierba.

Así que sepan todos, propios y extraños,

que estos versos los compuso, en medio de sus estudios,

Embrico, a quien encumbran conducta, linaje y cargos.

Quizás se quiera saber dónde nació este espíritu sutil:

lo voy a explicar sin ningún resquemor.

Era maguntino, al igual que su madre.

Conocía a los autores mayores y menores,

y los explicó convenientemente a quienes quiso.

Leyó a los filósofos, asimiló las Sagradas Escrituras, y comentó ampliamente cuanto le pareció mejor.

Si lo llegase a ver visto Nasón lo habría tenido

por un Sidonio en la prosa, y un Virgilio en el verso.

¿Para qué más detalles? Si queréis conocerlo,

fue moralista, lógico y naturalista.

Lozano de cuerpo, poseía un alma santa.

Deben pues los ancianos, los niños y los jóvenes

amar abiertamente la obra que escribió

para que, como el mago, no se pierdan, cuando pueden vivir.

Antes de nada, vale la pena comentar que la composición va referida inequívocamente al autor de la Vita Mahumeti, como demuestra su posición en los dos manuscritos antes citados y, sobre todo, la referencia del último verso al magus, que es el personaje principal del relato legendario sobre $\mathrm{Mu}$ hammad $^{5}$.

Entrando más a fondo en la forma y en el contenido de la semblanza, es destacable su tono elogioso, a la vez que familiar y un tanto desenfadado. Sería el tono esperable en un escrito compuesto por alguien del entorno más próximo a Embrico. Por lo demás, el uso de verbos en tiempo pasado (erat, nouerat, legerat, legit, exposuit, florebat, manebat, etc.) puede hacer pensar que el poema fue redactado una vez fallecido el homenajeado, pero esta conjetura no es por completo firme, pues esos tiempos verbales igualmente podrían interpretarse como referencias a una etapa

${ }^{5}$ Aunque una glosa al manuscrito de Berlin consigna que el término magus se refiere a Simón Mago, tiene más sentido asociarlo al mago instructor de Mamucius, pues el verso final vendría a invitar al lector a no incurrir en soberbia o desdén -los pecados que ocasionaron la perdición del mago- a la hora de enjuiciar la composición de Embrico. 
pasada de la biografía del personaje, sin presuponer necesariamente que éste ya haya muerto.

Por lo demás, el perfil que se ofrece de Embrico es, aunque un tanto vago, suficiente para obtener algunas claves importantes. En primer lugar, era miembro de una familia de la nobleza (quem genus exaltat) de Mainz (Moguntinus, mater ut eius erat), entendiendo por tal, bien la ciudad, bien la diócesis, que en los siglos centrales de la Edad Media comprendía un territorio bastante amplio. Aparece descrito como un letrado con una buena formación en las artes liberales y que pudo haber desempeñado tareas de magister, si bien las referencias a la exposición de los auctores (quibus hos uoluit legerat; quicquid ei placuit exposuit) no hacen pensar tanto en una enseñanza reglada como en un ejercicio magistral más libre. Además, Embrico ha disfrutado de honores, esto es, ha desempeñado cargos públicos de cierta relevancia, bien en la administración eclesiástica, bien en la secular. Mención aparte merece la expresión iste catus que, como en su día explicó Châtillon, juega con dos acepciones: la del adjetivo catus ("agudo", "sutil") y la del gentilicio cattus, que daba nombre a las antiguas tribus germánicas que residían en el límite con la Franconia, al Norte y Este del curso medio del Rin ${ }^{6}$.

Un problema particular plantea la interpretación del verso 4: hec quod composuit carmina dum studuit. A primera vista parece indicar que el poema fue compuesto mientras el autor cursaba estudios, lo que invitaría a considerarlo, como sospechaba Beaugendre, una obra de juventud y tal vez un mero ejercicio literario. No obstante, cabría proponer para dum studuit el sentido alternativo: "al tiempo que estudiaba el asunto", o incluso una acepción próxima a la del adverbio studiose: "con tesón", "apasionadamente", pudiendo entonces explicarse la selección de la subordinada temporal por el condicionamiento de la rima con composuit.

A partir de la publicación de este testimonio, puede decirse que se abandonó la antigua atribución del poema a Hildeberto. De hecho, ya Strecker había apuntado sensibles diferencias en materia estilística y de técnica métrica entre la Vita Mahumeti y las composiciones del arzobispo de Tours ${ }^{7}$. Por otra parte, y al margen ya de las informaciones de la Vita auctoris, el hecho de que en los versos 421-422 de la Vita Mahumeti se reproduzca literalmente el epitafio del emperador Otón I en Magdeburgo, compuesto poco después de su muerte en 971 , hace pensar que el autor es un poeta alemán, no francés. A Mainz como punto de arranque de, al menos, una rama de la tradición manuscrita del poema apunta también el hecho de que el códice Bruxelles, Biblio-

\footnotetext{
${ }^{6}$ Châtillon 1965, pp. 91, 97.

${ }^{7}$ Strecker 1933, pp. 565-566.
} 
thèque Royale, Ms. 8883-8894 transmita, inmediatamente antes del poema sobre Muhammad (ff. 77-99), una Vita Adalberti Moguntini Archiepiscopi (ff. 54-76), esto es, una biografía métrica de Adalberto I, arzobispo de Mainz entre 1111 y 1137. Así, tanto los editores más recientes del poema, Fritz Hübner y Guy Cambier, como los restantes investigadores que se han ocupado de su estudio siempre han dado por buena la autoría de Embrico.

Aseguradas estas ideas, pasamos a debatir la cuestión de la identidad concreta del poeta. La primera hipótesis, formulada por Wattenbach y asumida ulteriormente por los dos editores modernos del texto, pero también por muchas otras autoridades, entre las cuales cabe destacar a Max Manitius, fue la de identificar al autor con un Embrico, preboste de Mainz y ulteriormente obispo de Augsburgo entre 1064 y 1077. Así las cosas, si el poema fue escrito, como parece sugerir la Vita auctoris, en la etapa de juventud de su autor, habría que datarlo en una fecha anterior al desempeño del cargo episcopal, hacia mediados del siglo XI, o incluso antes ${ }^{8}$.

En este punto, el problema de la autoría entra en intersección directa con el de la fecha de composición del texto. A falta de otras informaciones sobre la trayectoria del obispo de Augsburgo que pudiesen encajar con el perfil esbozado en la Vita auctoris, Guy Cambier ofreció un argumento, basado en una novedosa interpretación del contenido del poema sobre Muhammad, que permitiría corroborar su datación alrededor del año 1040. Según Cambier, el poema ofrece referencias veladas a sucesos que tuvieron lugar en la corte bizantina entre los años 1034 y 1041, a saber, las intrigas que urdió el eunuco Juan Orfanótropos para promover la subida al trono de su hermano, Miguel IV, previo enlace de éste con la emperatriz Zoe, que había quedado viuda del anterior soberano, Romano Argyros ${ }^{9}$. En efecto, son llamativas algunas coincidencias entre ambos relatos, por ejemplo, el origen humilde de Miguel, hijo de un campesino de la Paflagonia, y su condición de epiléptico (como Mamucius), las oscuras circunstancias de la muerte de Romano (como el cónsul, que muere asesinado) o el propio hecho de que Juan Orfanótropos hubiese sido el auténtico gobernante en la sombra a lo largo del reinado de Miguel (como el mago). Sin embargo, parece poco probable que el poema deba sea interpretado, en palabras de Cambier, como un roman à clef dirigido a la vez contra el profeta del islam y contra la corte bizantina, máxime cuando la mayor parte de los detalles en causa se explican perfectamente como desarrollos de tradiciones pseudohistoriográficas cristianas sobre Muhammad anteriores al siglo XII.

\footnotetext{
${ }^{8}$ Remito a Manitius 1923, vol. II, pp. 582-596, quien, a su vez, cita una referencia al personaje en Lamperti Hersfeld, Annales ann. 1064: "Heinricus Augustensis episcopus obiit (...) Embricho ei successit, praepositus Mogontinus, uir pontificalis modestiae et grauitatis".

${ }^{9}$ Cambier 1957, pp. 476-478.
} 
Por lo demás, contra la hipótesis de datar el poema en los años centrales del siglo XI se pueden dar algunos argumentos de peso. Por una parte, siendo los manuscritos que transmiten la Vita Mahumeti en su mayor parte de la segunda mitad del siglo XII o inicios del XIII, no contamos con ningún indicio de una posible circulación, conocimiento o uso del texto en la segunda mitad del siglo XI. Además, como señaló Von den Steinen, la fórmula métrica del dístico con rima interna, aplicada a la poesía narrativa, triunfó sólo a partir del último tercio del siglo $\mathrm{XI}^{10}$. Pero el razonamiento más eficaz deriva de la evaluación del contenido del poema, que encaja mejor en el arco temporal que va desde el último cuarto del siglo XI hasta mediados del siglo XII, época en que tuvieron lugar las dos primeras cruzadas (1096-1099; 1147-1149) y en que fueron redactados relatos fabulosos sobre Muhammad afines al de Embrico, como la noticia contenida en los Dei gesta per Francos de Guibert de Nogent (1109), el poema Otia de Machomete de Gautier de Compiègne (compuesto entre 1137 y 1155), o la Vita atribuida a Adelfo (escrito hacia 1150), sin olvidar otras semblanzas del personaje más acordes con las tradiciones musulmanas, como la que contiene el quinto de los Dialogi aduersus Iudeos de Pedro Alfonso (compuesto en 1110), o la versión árabe del anónimo Liber denudationis (compuesto entre 1085 y 1132) ${ }^{11}$.

De hecho, como a menudo se ha señalado, los colectivos cristianos que, entre los siglos VIII y XI, elaboraron y pusieron en circulación las primeras tradiciones relativas a la vida de Muhammad fueron los dimmíes de Oriente, los cronistas bizantinos y los mozárabes andalusíes. En el resto de la Europa continental e insular, en el periodo anterior a las dos primeras cruzadas, la situación era de ignorancia y de desinterés por esta cuestión, hasta el punto de que el discurso dominante sobre la religión islámica se limitaba a describir ésta como una reedición de la antigua idolatría pagana e identificaba al propio Muhammad como una suerte de ídolo tutelar, al que los musulmanes hacían sacrificios y consultaban a manera de oráculo, cuando no como una manifestación del mismo Anticristo ${ }^{12}$. Esta imagen perduró a lo largo de todo el siglo XII y aún más allá, pero ya no de forma hegemónica, pues desde fines del siglo XI fue elaborándose y difundiéndose una visión de signo muy distinto, que consideraba la religión musulmana como una herejía derivada del cristianismo y contaminada con creencias y ritos propios del judaísmo. Saltó así al primer plano la cuestión de los orígenes del islam, y ello propició un interés creciente por la figura misma de su fundador Muhammad,

\footnotetext{
${ }^{10}$ Von den Steinen 1933, pp. 279-283.

${ }^{11}$ Para una visión en conjunto de esta literatura, remito a Tolan 2002, pp. 135-155.

${ }^{12}$ Existe una amplísima bibliografía sobre el particular. A efectos de simplificación, remito una vez más a Tolan 2002, pp. 105-134.
} 
ya no en su faceta de ídolo o dios, sino como personaje histórico, en cuya biografía sería posible obtener claves importantes para la explicación del nuevo credo. Naturalmente, este interés creciente por el Profeta era nutrido por un caudal de informaciones de mejor o peor calidad procedentes de Oriente y de Hispania. Las peregrinaciones a los Santos Lugares, así como la constitución del reino cruzado de Jerusalén, permitieron una toma de contacto directo con los discursos sobre Muhammad y el islam que circulaban en Bizancio y en los países de su entorno, como Palestina o Armenia. Un proceso semejante se daba al mismo tiempo en la Península Ibérica, de la mano de los avances de los reinos cristianos sobre la al-Andalus musulmana y la expansión de Cluny por los centros monásticos y episcopales de Galicia y la Meseta. Así las cosas, la mayor parte de los estudiosos recientes se pronuncian por una datación del poema no anterior a los años de la primera cruzada, esto es, posterior a 1095.

Tras estas consideraciones en torno al probable periodo de composición del poema, retomemos la cuestión de la autoría. La hipótesis más aceptada entre los estudiosos recientes es la que, en un escrito publicado póstumamente, lanzó el propio Wattenbach, quien identificó a Embrico con un homónimo diácono de la catedral de Mainz, que desempeñó las funciones de tesorero entre 1090 y $1112^{13}$. Sin embargo, esta propuesta se apoya únicamente en la coincidencia en el nombre, el lugar de actividad (que no el de origen) y el periodo aproximado en que el poema pudo ser compuesto; nada aporta en lo relativo a los restantes rasgos del perfil esbozado por la Vita auctoris, por ejemplo, la pertenencia a una familia de la nobleza local o el desempeño de algún tipo de cargos que alcanzasen la categoría de honores. Así las cosas, parece necesario buscar alguna vía de aproximación diferente al problema que nos ocupa.

Un indicio que todavía no hemos sometido a examen es el que ofrece la mención expresa en el verso 73 de la Vita Mahumeti del nombre del dedicatario del poema: Godeboldus. Hübner identificó a este personaje con un homónimo diácono de la catedral de San Martín en Mainz, fallecido en $1056^{14}$. Por su parte, Francesco Stella ha propuesto recientemente dos hipótesis alternativas que encajarían en cada uno de los periodos entre los que, como hemos visto, los estudiosos han situado a Embrico: mediados del siglo XI, y finales del XI, inicios del XII. O bien se trataría de un Godeboldo advocatus del obispo de Mainz en 1040, o bien de un homónimo obispo de Utrecht entre 1114 y $1127^{15}$. Sin embargo, como ya advirtió Von den Steinen, el nombre es

\footnotetext{
${ }^{13}$ Wattenbach-Holtzmann 1948, p. 450. Consideran probable esta hipótesis Southern 1962, p. 30, n. 1; Petrus 2005, p. 1093; Tolan 2011, pp. 592-595.

${ }^{14}$ Hübner 1934, p. 154 ( $c f$. Von den Steinen 1933, p. 283, n. 22).

${ }^{15}$ Stella 2008, p. 125.
} 
tan corriente en la región de Mainz durante este periodo que los candidatos podrían multiplicarse. En todo caso, de la expresión usada en el poema, Godebolde, speculum summorum uirorum, cabe inferir que Godeboldo sería un hombre relativamente importante, tanto por linaje como por la posición social que ocupase en virtud de sus cargos, y que tenía sobre Embrico el suficiente ascendiente como para ordenarle redactar una exposición sobre el origen de la religión musulmana (v. 76: precipis, expediam; precipis et faciam).

Hasta aquí el estado de la cuestión. Vamos a exponer a continuación una propuesta alternativa sugerida en su día por Valentin Rose, el autor del catálogo de los manuscritos del fondo Phillipsiano de la Staatsbibliothek de Berlin ${ }^{16}$, pero ignorada, hasta donde he podido comprobar, por los estudiosos que se han ocupado de esta cuestión. Se trata de la identificación del autor de la Vita Mahumeti con Embrico, obispo de Würzburg entre 1127 y 1146.

Sobre este personaje contamos con una información algo más detallada que la disponible para el homónimo obispo de Augsburgo del siglo XI. Miembro de una familia aristocrática de la diócesis de Mainz, tuvo relación en su juventud con el poeta Hugo Metellus ( $c a .1080-1150$ ), lo que hace pensar que se formó en la escuela catedralicia de Toul, en la Lorena ${ }^{17}$. Su carrera, patrocinada por el obispo de Mainz Adalberto I (1111-1137), comenzó con un puesto de preboste en la catedral de Sta. María de Erfurt (1118-1127), pero al mismo tiempo, entre 1125 y 1127, fue miembro de la cancillería regia, bajo el emperador Lothar III von Supplinburg (1125-1137). El apoyo del arzobispo Adalberto y del emperador lo promovió al obispado de Würzburg en 1127, puesto que conservó hasta su muerte, en Aquileia, en 1146. De su labor en el obispado cabe citar la fundación de varias abadías cistercienses (Ebrach, Wechterswinkel) y premostratenses (Oberzell), la laudatio funebris que pronunció en 1139 con ocasión del funeral de Otto von Bamberg, el llamado apóstol de la Pomerania, y su condición de representante diplomático del emperador Conrado III en la boda del emperador bizantino Manuel I Comeno con Bertha von Sulzbach ${ }^{18}$.

Conservamos una carta de Hugo Metellus dirigida a Embrico, datable en los primeros años del episcopado de éste en Würzburg. En ella evoca la amistad de años antes y elogia las dotes intelectuales del nuevo obispo ${ }^{19}$.

\footnotetext{
${ }^{16}$ Rose 1893,p. 408.

${ }^{17}$ Nótese que el manuscrito de la Staatsbibliothek de Berlin, procedente de St. Arnould de Metz, contiene tanto la Vita Mahumeti de Embrico (ff. 105r-111v.) como piezas de Hugo Metellus (ff. 139r-185r).

${ }^{18}$ Una biografía antigua y detallada de Embrico puede consultarse en la compilación de Ludewig, et al. 1713, pp. 499-508. Una reseña más breve y moderna es la de Wendehorst 1959 p. 474.

${ }_{19}$ Esta epístola puede consultarse en el volumen misceláneo editado por Hugo 1731, pp. 353-354.
} 
Audiui te uigere consilio, pollere eloquio; audiui et credidi, memini enim tui uiuacis ingenii, tenacis memoriae, elegantis eloquentiae (...) Certus sum equidem te de profectu meo gratulari et antiquae iocundaeque familiaritatis nostrae te saltem in profestis diebus reminisci.

Pero contamos con otra interesante muestra de las dotes literarias de Embrico; se trata de un poema de 102 hexámetros leoninos que lleva por título Confessio Imbriconis episcopi Wirzburgensis y que dio a conocer Wattenbach en $1877^{20}$. Como es propio de este subgénero de la literatura penitencial, el texto consiste en una retórica lamentación, transida de arrepentimiento y temor de Dios, por los delitos y faltas cometidos a lo largo de la existencia pasada:

Cum bene perpendo quis sim, male semper agendo

Numquam cessando, sed prisca nouis cumulando,

Tunc me preteritae confundit ineptia uitae

Et lacrimas fundo, sic ore loquens tremebundo (vv. 1-4).

A pesar de ser textos de carácter muy diferente, la comparación entre la Confessio y la Vita Mahumeti deja ver algunas coincidencias en el uso de rimas y estructuras sintácticas, como por ejemplo:

Confessio, v. 58: Nullus dampnatus fuit umquam tam sceleratus.

Vita Mahumeti, v. 321: ad se dampnatum uocat ille suum sceleratum.

Vita Mahumeti, v. 847: Qua lue dampnatum magus ut uidet hunc sceleratum.

Confessio, v. 73: $\quad$ Quando narratur stirps regia uel numeratur.

Vita Mahumeti, v. 35: Quae cum narrare nullus queat aut numerare.

Confessio, v. 15: $\quad$ Nilque fuit blandum nisi constitit esse nefandum.

Vita Mahumeti, v. 797: Nil fuit humanum nisi constitit esse profanum.

Además de estas constataciones, es posible ofrecer un argumento más para identificar a nuestro poeta con el obispo de Würzburg. Me refie-

\footnotetext{
${ }^{20}$ Wattenbach 1877 , pp. 404-407.
} 
ro a la figura del dedicatario Godeboldus, a quien antes hice referencia. En la época en que Embrico desempeñaba el obispado, el noble Godebold II (1070-1144), conde de Henneberg desde 1096, era el castellano (burgrave) de Würzburg. Así pues, en cuanto aristócrata con ascendiente directo sobre Embrico, su perfil se adecúa bien a la breve mención contenida en los versos 73-76 del poema.

En resumen, la biografía del obispo de Würzburg Embrico concuerda con el mínimo perfil esbozado en la Vita auctoris: noble maguntino, dotado de una buena formación en las artes liberales y titular de diversos cargos (honores) en la administración imperial y eclesiástica. Es, además, poeta de verso leonino y se advierten, al menos, algunas semejanzas formales entre la Confessio y la Vita Mahumeti. También encaja con esta hipótesis su relación directa con un aristócrata llamado Godebold, sin olvidar la consideración de la tradición manuscrita del poema, una de cuyas ramas nos lleva a Metz, ciudad de la Lorena próxima a Toul, donde se habría formado Embrico.

En cuanto a las fechas concretas en que pudo haber sido compuesto el poema, cabe suponer que es anterior a 1127, año de inicio del obispado. Si interpretamos la frase de la Vita auctoris "dum studuit" en el sentido de "mientras era estudiante", habría que fecharlo durante el periodo de formación en Toul, esto es, antes de 1118. Si optamos por entenderla como una mera variante del adverbio studiose: "esforzadamente", la data de composición podría retrasarse hasta los años de preboste en Erfurt, entre 1118 y 1127.

En apoyo de esta propuesta es posible añadir otra observación más. Según la Crónica de Richard de Cluny, compuesta a mediados del siglo XII, los errores que alberga el Corán eran bien conocidos en Francia a través de un poema ${ }^{21}$. Aunque se ha defendido la idea de que este poema fuese el titulado Otia de Machomete, de Gautier de Compiègne, parece más probable que se trate de la Vita Mahumeti de Embrico, pues tenemos constancia de que a mediados del siglo XII circulaba ya en diversas antologías por bibliotecas cluniacenses de Francia. Y si, como suponemos, el poema fue compuesto hacia 1120 , habría tenido tiempo suficiente para difundirse ampliamente, sin perder, con todo, actualidad.

\footnotetext{
21 "Scripsissem et enim de eo plura nisi errores libri eius iam publice in Francia a quodam metrice scripti legerentur". Este texto puede consultarse en Di Cesare 2012, p. 167. Por lo demás, la datación de la Crónica de Richard de Cluny es incierta, cuestión que se complica por el hecho de que tuvo varias redacciones. Con todo, es posible efectuar una cierta aproximación de acuerdo con las siguientes constataciones: a) el autor murió hacia 1170; b) en alguna de las redacciones figura una dedicatoria a Pedro el Venerable, quien murió en 1156/7; c) en la Crónica, el maestro cristiano de Muhammad se identifica con el nestoriano Sergio, dato que procede con seguridad de los escritos sobre el islam de Pedro el Venerable, posteriores a 1142-1143. Así, la obra podría fecharse entre 1143 y 1156/7.
} 
Obviamente, subsisten algunas dificultades. Por ejemplo, no tenemos constancia de que el futuro obispo de Würzburg hubiese desempeñado en algún momento de su carrera la labor docente, como se indica en la Vita auctoris, si bien su puesto como preboste en Erfurt pudo dar lugar a alguna actividad de este tipo.

Por otra parte, si estamos ante un personaje tan señalado en el ámbito eclesiástico y político, ¿por qué razón se habrían de silenciar estos rasgos de su biografía en la Vita auctoris? Tal vez por un cierto sentido del decoro o la prudencia. Ya en el momento de la composición el autor se había mostrado humilde y temeroso de que la difusión pública del poema pusiese en evidencia sus defectos:

Quodsi dignatur Deus ut ceptum peragatur, dum tua iussa sequor, sic lege nostra precor ne transcribantur aut a multis uideantur.

Nostra timent uicia publica iudicia (vv. 79-82).

Es de suponer que años después, cuando Embrico ya era un alto cargo eclesiástico dotado de ciertas responsabilidades en la cancillería imperial, no considerase un activo a su favor el hecho de haber compuesto en su juventud un poema de tono satírico y argumento novelesco, en el que pasajes característicos de la literatura piadosa, como la descripción de las penas del infierno o la evocación de los martirios, alternan con otras muestras de un humor grotesco y corrosivo. ¿Se referirán precisamente a esta composición las ligerezas y pasatiempos de juventud evocados en los versos de la Confessio?

En ego confusus antiquos cogito lusus

Quasque per etates uarias feci leuitates (vv. 12-13).

Si se da por buena la hipótesis que acabamos de exponer y desarrollar, es preciso valorar las consecuencias que tiene para el tratamiento de algunos de los aspectos de la Vita Mahumeti.

Tenemos, en primer lugar, la cuestión de las fuentes del poema. El autor no da ninguna indicación al respecto, y la evaluación del problema por parte de los editores y restantes estudiosos siempre ha estado condicionada por la incierta datación del texto. Así, Cambier, que situaba a Embrico a mediados del siglo XI, consideraba que podría haber aprovechado informaciones orales procedentes de peregrinos a Jerusalén o de contactos comerciales y diplomáticos con el imperio bizantino, si bien también habría hecho uso de la Historia Ecclesiastica de Anastasio Bibliotecario y de los escritos de los cordobeses del siglo IX Eulogio y Paulo Álbaro, 
donde encontró una serie de correspondencias con la Vita Mahometi muy poco convincentes ${ }^{22}$.

Estudiosos posteriores, que se pronunciaron por fechar el poema en la época de la primera cruzada, se limitaron a señalar la afinidad del relato de Embrico con otras pseudo-biografías de Muhammad de semejante tenor compuestas en la primera mitad del siglo XII, como las de Guibert de Nogent, Gautier de Compiègne y Adelfo, y no fueron mucho más allá de suponer que todas reflejaban un estado de opinión general entre la clerecía contemporánea respecto del origen del islam, que se habría conformado básicamente a partir de tradiciones orales procedentes de Bizancio y los restantes colectivos de la cristiandad oriental ${ }^{23}$.

Sin descartar en absoluto esta última hipótesis, intentaremos hacer una propuesta más específica partiendo de la premisa de que la Vita Mahumeti fue compuesta hacia 1120 o pocos años antes. Si esto es así, cabría admitirse como probable el conocimiento de la noticia sobre Muhammad presente en los Dei gesta per francos de Guibert de Nogent, obra compuesta en 1109 y que, a buen seguro, tuvo una amplia difusión en el intervalo entre la primera y la segunda cruzada. Es cierto que el relato de Guibert muestra sensibles diferencias con el de Embrico: por ejemplo, el instructor de Muhammad es un heresiarca aspirante al patriarcado de Alejandría, no un mago que intenta hacerse patriarca de Jerusalén; la vaca portentosa lleva en sus cuernos un libro de leyes, no una inscripción que confirma la condición regia de Muhammad; Guibert no menciona el motivo del sepulcro flotante etc., pero, en mi opinión, la mayor parte de esas diferencias podrían justificarse como desarrollos ideados por Embrico a partir del esquema narrativo básico que le habría suministrado la noticia de Guibert, y que comprendería los motivos del instructor cristiano, el matrimonio con la viuda, el prodigio de la vaca y la muerte y profanación del cadáver. La hipótesis inversa, a saber, que Guibert hubiese seguido a Embrico (en el supuesto de que la Vita Mahumeti fuese anterior a 1109) es inviable, pues el relato de Guibert refleja más fielmente que el de Embrico aspectos de la leyenda de Muhammad procedentes de la cristiandad oriental, como es el prodigio de la vaca portadora del Corán, ya recogido en la leyenda siro-árabe de Sergio-Bahīirā̃ ${ }^{24}$.

Con respecto al sentido de la obra, su intencionalidad y su papel en la historia de la controversia ideológica entre islam y cristianismo, me parece necesario introducir algún matiz en su valoración, a la luz de algunas de

${ }^{22}$ Cambier 1962, pp. 35-37.

${ }^{23}$ Tolan 1996, 2002, pp. 144-147; Stella 2008, pp. 123-127. Petrus 2005, p. 1100

${ }^{24}$ Edición y traducción de las distintas recensiones sirias y árabes en Roggema 2009. 
las consideraciones antes expuestas. Si es verdad que nos encontramos ante una obra de juventud, de la que el autor se habría distanciado abiertamente en su madurez y si, desde otro punto de vista, reconocemos que comporta un importante ingrediente de fabulación personal, parece necesario entenderla no tanto como un reflejo preciso del conocimiento sobre el islam que circulaba por la Europa central en las primeras décadas del siglo XII, ni tampoco como un ejercicio serio de propaganda contra el islam. Tendría más sentido ver en ella un lusus, un irreverente divertimento a propósito de Muhammad, análogo al plasmado en el otro poema latino medieval sobre este personaje, los Otia de Machomete de Gautier de Compiègne. No quiero decir con ello que el contenido del poema carezca de un acusado componente ideológico, relativo a la categorización del islam como una religión falsa, burda e inmoral, o pragmático, en la idea de que su amplia difusión habría contribuido a suscitar un ambiente de cruzada, pero, al margen de estas cuestiones, el poema puede ser leído también como un ejercicio literario de sátira, parodia, combinación bufa de ingredientes patéticos y cómicos, y partícipe de ese espíritu a la vez cultista, vitalista e irreverente propio de la poesía de la época.

Para finalizar, y a título meramente anecdótico: la propuesta de identificar el autor de la Vita Mahumeti con Embrico obispo de Würzburg tiene una ventaja más, la posibilidad de adjudicar un rostro -todo lo imaginario que se quiera- al personaje. En efecto, se conserva un retrato de Embrico, hecho en 1713 por el grabador Johann Salver. Lleva el epígrafe comes a Leiningen, por el hecho de que las biografías antiguas del obispo lo consideraban miembro de este linaje, opinión hoy descartada. El retrato aparece en la colección de estampas de Salver titulada Die Gross und Landmeister des Deutschen Ordens, Würzburg, 1716 25, y también en el folio 498 de la compilación de biografías de eclesiásticos de Würzburg: Geschicht Schreiber von den Bischoffthum Wirtzbürg, Frankfurt, Thomas Fritschen, $1713^{26}$.

${ }^{25}$ Accesible en: http://www.portraitindex.de/documents/obj/34022342 [consulta: 28/06/2017].

${ }^{26}$ Accesible en: http://digital.bibliothek.uni-halle.de/hd/content/pageview/682159 [consulta: 28/06/2017]. 


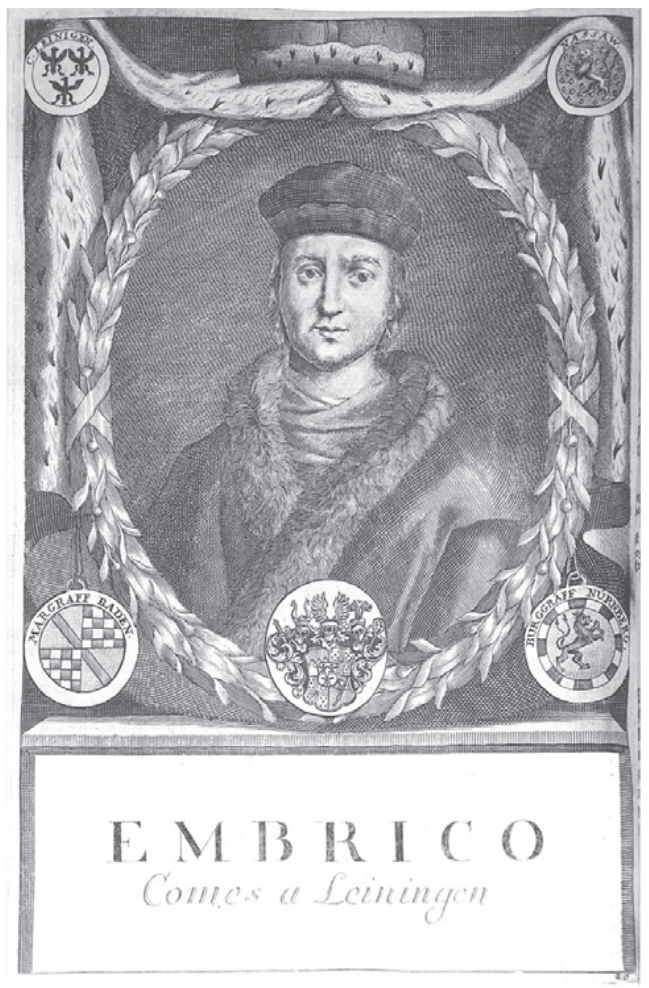

Fig 1. Salver 1713, p. 497.

\section{BIBLIOGRAFÍA CITADA}

Beaugendre, Antoine (1708), Venerabilis Hildeberti primo Cenomanensis Episcopi, deinde Turonensis archiepiscopi opera omnia tam edita quam indedita. Acceserunt Marbodi Redonensis episcopi, ipsius Hildeberti supparis opuscula, París, Laurente Le Conte, pp. 1277-1296 [reimpresión en Patrologia latina, vol. 171, col. 1343-1366. París, 1854].

Cambier, Guy (1957), Embricon de Mayence (1010?-1077) est-il l'auteur de la "Vita Mahumeti"?, "Latomus" 16/3, pp. 468-479.

Cambier, Guy (1962), Embricon de Mayence, La vie de Mahomet, Bruselas, Coll. Latomus.

Châtillon, François (1965), Embricon de Mayence, "Iste catus", "Revue du Moyen Âge latin. Études, textes, chroniques, bibliographie LyonStrasbourg" 21, pp. 88-98. 
Di Cesare, Michelina (2012), The Pseudo-historical Image of the Prophet Muhammad in Medieval Latin Literature. A Repertory, Berlín - Boston, De Gruyter.

Hübner, Fritz (1934), Die Grabschrift Ottos I. im Magdeburger Dom, "Historische Vierteljahrsschrift, Zeitschrift für Geschichts-wissenschaft und für lateinische Philologie des Mittelalters" 28, pp. 154-155.

Hübner, Fritz (1935), Vita Mahumeti, "Historische Vierteljahrsschrift, Zeitschrift für Geschichtswissenschaft und für lateinische Philologie des Mittelalters" 29, pp. 441-490.

Hugo, Carlo Ludovico (1731), Sacrae Antiquitatis Monumenta, Historica, Dogmatica, Diplomatica, tomus II, Sancti Deodati (Saint Dié), typis Josephi Charlot.

Ludewig, Johann Peter (1713), Geschicht Schreiber von den Bischoffthum Wirtzbürg, Francfurt, Thomas Fritschen.

Manitius, Max (1923), Geschichte der Lateinischen Literatur des Mittelalters, vol. II, Múnich, C.H. Beck.

Petrus i Pons, Nàdia (2005), La "Vita Mahumeti" de Embrico de Mainz, en Díaz y Díaz, Manuel C.; Díaz de Bustamante, José Manuel (eds.) Poesía latina medieval (siglos V-XV), Florencia, SISMEL - Edizioni del Galluzzo, pp. 1091-1100.

Roggema, Barbara (2009), The Legend of Sergius Bahīrā: Eastern Christian Apologetics and Apocalyptic in Response to Islam, Leiden - Boston, Brill.

Rose, Valentin (1893), Verzeichniss der Lateinischen Handschriften der Königlichen Bibliothek zu Berlin, Ersted Band: Die Meermann-Handschriften des Sir Thomas Philipps, Berlín, Asher.

Salver, Johann (1716), Die Gross und Landmeister des Deutschen Ordens, Würzburg.

Southern, Richard William (1962), Western Views of Islam in the Middle Ages, Cambridge, Mass. - Londres, Harvard University Press.

Stella, Fracesco (2008), Le versificazioni latine della vita di Maometto. Dall' antiagiografia al romanzo picaresco, en Stotz, Peter; Roelli, Philip (eds.) Dichten als Stoff-Vermittlung. Formen, Ziele, Wirkungen. Beiträge zur Praxis der Versifikation lateinischer Texte im Mittelalter, Zúrich, Chronos, pp. 119-150.

Strecker, Karl (1933), Embrico, en Die Deutsche Literatur des Mittelalters, Verfasserlexicon, Berlín - Leipzig, [s.n.], vol. I, pp. 565-566.

Tolan, John Victor (1996), Anti-Hagiography: Embrico of Mainz's Vita Mahumeti , "Journal of Medieval History" 22, pp. 25-41.

Tolan, John Victor (2002), Saracens. Islam in the Medieval European Imagination, Nueva York, Columbia University Press. 
Tolan, John Victor (2011), Embrico of Mainz, en Thomas, David; Mallet, Allet (eds.), Christian-Muslim Relations. A Bibliographical History, vol. 3 (1050-1200), Leiden - Boston, Brill, pp. 592-595.

Von den Steinen, Wolfram (1933), Literarische Anfänge in Basel, "Basler Zeitschrift für Geschichte und Altertumskunde (Basel)" 32, pp. 240-288.

Wattenbach, Wilhelm (1877), Bericht über eine Reise durch Steiermark im August 1876, "Neues Archiv der Gesellschaft für ältere deutsche Geschichtskunde" 2, pp. 385-425, URL: http://www.digizeitschriften.de/dms/img/?PPN=PPN345858530_0002\&DMDID=dmdlog28 \&PHYSID=phys421 [consulta: 28/06/2017].

Wattenbach, Wilhelm (1891), Lateinische Gedichte aus Frankreich im elften Jahrhundert, "Sitzungsberichte der Königlich Preussischen Akademie der Wissenschaften zu Berlin" 1, pp. 97-114.

Wattenbach, Wilhelm; Holtzmann, Robert (1948), Deutchslands Geschichtsquellen im Mittelalter, Tubinga, Matthiesen.

Wendehorst, Alfred (1959), Embrico, en Stolberg-Wernigerode, Otto de (ed.), Neue Deutsche Biographie. Band 4, Berlín, Duncker \& Humblot, p. 474, URL: http://daten.digitale-sammlungen.de/bsb00016320/ image_488 [consulta: 28/06/2017].

Fecha de recepción del artículo: febrero 2015

Fecha de aceptación y versión final: junio 2015 